\title{
A visão do educador da primeira infância frente à importância do seu trabalho
}

\author{
Carolina Pasquini Ribeiro ${ }^{1}$ e Orly Zucatto Mantovani de Assis ${ }^{1}$
}

\author{
${ }^{1}$ Laboratório de Psicologia Genética - Faculdade de Educação - Universidade Estadual de \\ Campinas, Brasil | carolpasquini@hotmail.com; orly.zma@gmail.com | https://orcid.org/0000- \\ 0001-9129-6000; https://orcid.org/0000-0003-3751-5940
}

Resumo: Atualmente, no Brasil, aproximadamente 3 milhões de crianças de 0 a 3 anos de idade encontram-se matriculadas em instituições escolares. Porém, dado inúmeras concepções que norteiam o desenvolvimento infantil, muitos educadores dessa faixa etária permanecem imbuídos por ideias distorcidas, tornando-se alheios à sua importância social e, principalmente, para com o pleno desenvolvimento do sujeito. Objetivou-se nesta pesquisa investigar o impacto da formação dos profissionais de educação que trabalham com crianças de 0 a 2 anos de idade para o contexto educacional em que atuam. Trata-se de uma pesquisaação, da qual participaram 19 auxiliares de educação responsáveis pelo atendimento de 71 crianças entre 4 e 24 meses de idade, em escolas de uma rede pública municipal. A investigação ocorreu em 3 etapas: exploratória, de ação e de avaliação. Este artigo apresenta uma das etapas desenvolvidas, a etapa exploratória. Atividades integradas e complementares compuseram a coleta de dados nesta etapa, entre elas: entrevista aberta em grupo focal, sessões de observação participante em sala de aula, revisão de documentos, entrevista semiestruturada individual e um teste situacional. As respostas obtidas durante as etapas foram categorizadas de acordo com seu conteúdo, o que possibilitou o tratamento das informações. Entre os resultados encontrados neste momento concluiu-se que o contexto educacional em questão permanecia fundamentado por concepcões assistencialistas, as quais determinavam uma série de comportamentos que influenciavam o atendimento às crianças pequenas; o não conhecimento do como ocorre o desenvolvimento da criança pequena por parte das participantes não propiciava práticas favoráveis a criança; a desvalorização das profissionais de educação não as levava a notar sua importância frente ao desenvolvimento das crianças de 0 a 2 anos de idade.

Palavras-chave: Pesquisa-ação; Primeira Infância; Contexto Educacional; Desenvolvimento Infantil.

\section{The Early Childhood Educator's View of the Importance of his Work}

Abstract: Currently, in Brazil, approximately 3 million children aged 0 to 3 years old are enrolled in school institutions. However, given the accumulation of concepts that guide child development, many educators in this age group remain imbued with distorted ideas, becoming alien to their social importance and, mainly, to the full development of the subject. The objective of this research was to investigate the impact of the training of education professionals who work with children from 0 to 2 years of age for the educational context in which they work. This is an action research, with the participation of 19 education assistants responsible for the care of 71 children between 4 and 24 months of age, in schools of a public municipal network. The investigation took place in 3 stages: exploratory, action and evaluation. This article presents one of the stages developed, the exploratory stage. Integrated and complementary activities comprised data collection at this stage, including: open interview in a focus group, collection of participant observation in the classroom, document review, individual semi-structured interview and a situational test. The corresponding responses during the stages were categorized according to their content, which made it possible to process the information. Among the results found at this moment, it was found that the educational context in question remained based on assistentialist conceptions, such as which determined a series of behaviors that influenced the care of young children; the lack of knowledge of how the development of the young child occurs on the part of the participants did not provide childfriendly practices; the devaluation of education professionals was not as it led to notice its importance in the development of children from 0 to 2 years old.

Keywords: Action research; Early Childhood; Educational Context; Child Development. 


\section{Introdução}

Ao longo da história, a criança pequena vem ganhando espaço no contexto educacional e com isso levando inúmeros profissionais da educação e estudiosos a se perguntarem sobre quais são as reais necessidades da primeira infância e qual o papel da escola frente a elas?

Inúmeros são os fatores que englobam esta questão, porém, entre eles, a necessidade de pensar sobre como o sujeito aprende e quais aspectos fazem parte desse processo ganham destaque. Posto isto, este estudo fundamenta-se na teoria explicada pelo importante epistemólogo do século XX, Jean Piaget (1896 - 1980). Para o pensador, o conhecimento é adquirido através de estruturas orgânicas, as quais não aparecem como um mecanismo pronto e acabado em determinada fase da vida, nem tão pouco préformadas ou inatas, mas sim o produto de uma construção gradual, que supõe a existência de períodos com determinadas características essenciais.

Com relação à primeira infância, Piaget e Inhelder (1988) destacam que o período de $0 \mathrm{a}$ 2 anos de idade, do nascimento da inteligência, nomeado por ele de sensório-motor, período de inteligência puramente prática, constitui a base de toda atividade psíquica construtiva, afirmando que "os conhecimentos adquiridos posteriormente estão, se não pré-formados nele, amplamente condicionados pelas operações psíquicas da primeira fase da vida" (p.31). Partilhando desta ideia, o documentário O começo da vida (Renner, 2016, 1:03) aponta que "os primeiros anos são como construir a estrutura de uma casa. É a estrutura sobre a qual todo o resto se desenvolverá".

A esse respeito Mantovani de Assis e Mantoan (2010) asseguram que o meio desempenha um papel fundamental, oferecendo a matéria-prima para que a construção da inteligência chegue a um bom termo. Ou seja, o bebê que nasceu com todas as funções biológicas necessárias para vir a ser inteligente só conseguirá chegar às fases finais desse processo evolutivo dependendo das solicitações que o meio físico e social the possibilitar. Deste modo, torna finalidade da escola oferecer oportunidade para que 0 aluno possa construir seu conhecimento através da experiência.

Considerando que atualmente no Brasil grande parte das crianças de 0 a 3 anos de idade são atendidas em nível de creche, estabelecimento educativo que ministra apoio pedagógico e cuidados a crianças dessa faixa etária, julgamos necessário conhecer o trabalho realizado pelos profissionais de educação responsáveis, bem como os aspectos e concepções que podem vir a influenciar esse atendimento. Assim sendo, para responder ao nosso problema desenvolvemos uma pesquisa-ação, através da qual buscamos inicialmente conhecer este contexto sob a perspectiva de quem o compõe, no caso, auxiliares de educação (Etapa exploratória). Posteriormente, com base nos dados coletados partimos para oferta de uma formação profissional às participantes da pesquisa (Etapa de ação) e, por fim, avaliamos as mudanças relativas ao seu processo de formação, considerando suas novas e permanentes concepções, tal como as atuais práticas exercidas contexto educacional em questão (Etapa de avaliação).

Ressaltamos que este artigo discorre sobre a etapa exploratória da investigação acima mencionada, cujo objetivo geral visou investigar o impacto da formação dos profissionais de educação que trabalham com crianças de 0 a 2 anos de idade para o contexto educacional em que atuam. Para esta etapa específica objetivou-se conhecer a visão do educador da primeira infância frente à importância do seu próprio trabalho.

\section{Referencial Teórico}

Renomados estudiosos como Freud (1856-1939), Melaine Klein (1882-1960), Pikler (19021984), Winnicott (1896-1971), ao longo do tempo e de acordo com suas concepções apontam para a importância dos primeiros anos de vida para o desenvolvimento do sujeito (Ribeiro, 2020). Porém, como questionam Mantovani de Assis e Mantoan (2010, p.23) "de que recursos dispõe esse pequenino ser para resolver tantos problemas?" 
Inúmeras concepções norteiam o ato de conhecer. Porém, considerando as teorias que retratam a complexidade desse processo e as viviências das pesquisadoras enquanto professoras de Educação Infantil e/ou Ensino Fundamental I, a teoria proposta por Jean Piaget e seus colaboradores apresenta-se notada e, como comprovada por inúmeros pesquisadores, irrefutável, contribuindo para mais este estudo.

Segundo Piaget, o conhecimento procede de interações que se produzem entre o sujeito e o objeto, ou seja, o "estímulo" procedente do meio externo só sensibiliza e desencadeia uma resposta quando seus esquemas de ação podem interpretá-lo ou assimilá-lo (Mantovani de Assis \& Assis, 2003).

Piaget e Inhelder (1975, p.176) explicam o desenvolvimento como "um processo que diz respeito à totalidade das estruturas do conhecimento". Assim sendo, como aponta Ramozzi-Chiarottino (1988) é importante ressaltar que, de acordo com Piaget, existem três tipos de estruturas: as programadas (que nos capacitam a prever determinados comportamentos), as parcialmente programadas (cujo desenvolvimento e construção dependem em grande parte do meio) e as nada programadas (estruturas mentais, específicas para $\mathrm{o}$ ato de conhecer).

Para o epistemólogo Jean Piaget, a espécie humana traz possibillidades genéticas com relação às estruturas mentais, porém essas não são programadas, ou seja, podem ou não se atualizar de acordo com a solicitação do meio. Assim dizendo, para que ocorra a construção do conhecimento é necessário que sucedam trocas do organismo com o meio. Como explica Ramozzi-Chiarottino (1988, p.6) "essas trocas são responsáveis pela construção da própria capacidade de conhecer; sem elas, essa capacidade não se constrói".

Assim, dado a relevância deste período da vida e a importância da solicitação do meio para o pleno desenvolvimento do sujeito adentramos o contexto educacional de 0 a 2 anos de idade, o qual, no Brasil, como explica Kuhlmann Jr (1998) é resultado da articulação de interesses em torno de três influências básicas: a médico-higienista, o jurídico-policial e a religiosa.

De acordo com Coutinho (2002, p.9) "as amarras históricas que vinculam o cuidado ao atendimento assistencial, e estes, por sua vez, à educação da primeira infância condicionam as posturas educativas dos profissionais ao dimensionar o cuidado como menos importante ou talvez até desconsiderá-lo". Tadavia, como garante Bujes (2001, p.17) "a educação infantil envolve simultaneamente cuidar e educar, vamos perceber que esta forma de concebê-la vai ter consequências profundas na organização das experiências que ocorrem nas creches e pré-escolas".

\section{Metodologia}

Este artigo apresenta uma das etapas da pesquisa de mestrado intitulada: O contexto educacional e o desenvolvimento da inteligência da criança no período sensório-motor, realizada na Faculdade de Educação da Universidade Estadual de Campinas - Unicamp, no período de 2018 a 2020. Tal investigação foi aprovada pelo Comitê de Ética em Pesquisa da instituição proponente.

\subsection{Natureza do Estudo}

Para responder ao problema desta pesquisa, a abordagem investigativa utilizada foi a qualitativa. Metodologia aplicada a fim de compreender e aprofundar o tema a partir da perspectiva dos participantes, aprofundando suas experiências, pontos de vista, opiniões e significados, possibilitando assim a construção de novas questões e conceitos a partir do próprio estudo (Sampieri, Collado \& Lucio, 2013). 
Caracterizada como pesquisa-ação, tipologia da metodologia qualitativa, esse desenho de pesquisa segundo Tripp (2005, p. 447) visa sobre "uma forma de investigação-ação que utiliza técnicas de pesquisa consagradas para informar a ação que se decide tomar para melhorar a prática" e "ao mesmo tempo altera o que está sendo pesquisado e é limitado pelo contexto e pela ética da prática".

Segundo Sadín Esteban (2013), o alcance do objetivo proposto em uma pesquisa-ação se faz através de um ciclo que atividades, sendo elas: identificar o problema, torná-lo claro e diagnosticá-lo, elaborar um plano para solução ou melhoria do problema, implantar o plano e avaliar os resultados constituindo assim um feedback, o qual deve levar a um novo diagnóstico e espiral de reflexão e ação. Destaca-se que a pesquisa incluiu em seu primeiro momento, na etapa exploratória, a aproximação e imersão no contexto em estudo e posteriormente o acompanhamento e avaliação do processo.

\subsection{Participantes}

A pesquisa contou com a participação de 19 (dezenove) auxiliares de educação responsáveis pelo atendimento de 71 (setenta e um) crianças de 0 a 2 anos de idade, distribuidas em 4 (quatro) escolas de educação infantil em uma rede municipal de educação do interior do Estado de São Paulo, Brasil.

As auxiliares, mulheres entre 19 e 60 anos, de classe média, funcionárias púbicas efetivas ou temporárias, residentes no município de trabalho ou cidades vizinhas. Dessas, 7 (sete) concluíram o ensino médio, 4 (quatro) o magistério e 8 (oito) o Ensino Superior, sendo: 6 (seis) na área da Pedagogia, 1 (um) na área de História e 1 (um) na área de Direito.

\subsection{Instrumentos}

De maneira integrada e complementar foram utilizados como instrumentos para coleta de dados na etapa exploratória deste estudo: entrevista aberta em grupo focal, sessões de observação participante em sala de aula, revisão de documentos, entrevista semiestruturada individual e um teste situacional.

\subsection{Procedimentos}

A composição desta amostra deu-se a partir da aproximação da pesquisadora com o Departamento Municipal de Educação. Após explicação sobre a relevância social do estudo e sanada as dúvidas da equipe responsável (direção, coordenação e orientação pedagógica) a realização do estudo foi autorizada. Assim, foi entregue às participantes do estudo, bem como aos responsáveis legais pelas crianças atendidas no âmbito em questão, o Termo de Consentimento Livre e Esclarecido (TCLE). Dado o retorno deste, demos sequência a imersão no contexto em estudo, iniciando a etapa exploratória desta investigação.

Com vista a conhecer o contexto educacional sob o olhar das participantes do estudo, iniciou-se a entrevista aberta. Como descrita por Delval (2002), uma conversa direcionada por algumas hipóteses iniciais, que permite explorar um novo campo. Porém, neste momento foi constatada a insegurança das participantes em se expressarem - as mesmas aparentemente sentiam-se avaliadas. Dado este fato, a entrevista passou a acontecer em grupo focal. Segundo Kitzinger (2000), uma forma de entrevistas com grupos, baseada na comunicação e na interação. Prática que possibilita encontrar informações que favoreçam a compreensão de percepções, crenças, atitudes, produto ou serviços. Ao longo dos encontros, palavras-chave, ideias e reflexões foram registradas em caderno de campo para posterior análise.

O próximo passo foi a observação, elemento fundamental em diversos aspectos de uma pesquisa, visto que "(...) traduz descrições detalhadas de acontecimentos, pessoas, ações e objetos em determinado contexto" (Vianna, 2003, p.16). 
"A observação nada mais é que o uso dos sentidos com vistas a adquirir os conhecimentos necessários para o cotidiano" (Gil, 1987, p.104). Optou-se nesta investigação a fim de suprir inconvenientes como possíveis alterações no comportamento dos observados em adotar uma observação participante. A observação participante, ou ativa, equivale à participação real do observador na vida ou grupo, ou seja, o observador assume o papel de membro do grupo (Gil, 1987).

Em seguida, a fim de compreender e analisar as informações coletadas até o momento, buscou-se explorar de maneira qualitativa o Edital de Concurso Público para contratação das profissionais em questão.

Assim, dada as análises realizadas até o momento, se fez necessário conhecer as particularidades das participantes com relação ao contexto em que atuam, para isso utilizou-se a entrevista semiestruturada. Como explica Delval (2002) perguntas comuns para todos os sujeitos, mas que vão sendo ampliadas e complementadas de acordo com as repostas dos investigados para poder interpretar da melhor maneira possível o que vão dizendo. As questões básicas visaram analisar a importância da formação profissional, a valorização deste serviço e as necessidades da criança pequena. Cada entrevista levou em média 30 minutos, foram gravadas e posteriormente transcritas.

Por fim, foi elaborado pela pesquisadora um teste situacional envolvendo situações observadas e cotidianas no cenário educacional de 0 a 2 anos de idade.

Em suma os procedimentos desenvolvidos foram:

Quadro 1. Procedimentos utilizados na etapa exploratória

\begin{tabular}{|c|c|}
\hline Procedimento & Descrição \\
\hline $\begin{array}{l}1 \\
\text { Entrevista } \\
\text { aberta em } \\
\text { grupo focal }\end{array}$ & $\begin{array}{l}\text { Entrevista aberta realizada através de grupo focal } \\
\text { durante } 10 \text { horas de estudo, distribuídas em } 4 \\
\text { encontros. }\end{array}$ \\
\hline $\begin{array}{l}2 \\
\text { Observação } \\
\text { participante }\end{array}$ & $\begin{array}{l}\text { Observação participante (observador como } \\
\text { membro do grupo observado) realizada em } 12 \\
\text { sessões de aproximadamente } 60 \text { minutos cada, } \\
\text { distribuídas entre as } 4 \text { escolas participantes. }\end{array}$ \\
\hline $\begin{array}{c}3 \\
\text { Revisão de } \\
\text { documentos }\end{array}$ & $\begin{array}{l}\text { Análise do Edital de Concurso Público para o } \\
\text { cargo de Auxiliar de Educação. }\end{array}$ \\
\hline $\begin{array}{c}4 \\
\text { Entrevista } \\
\text { semiestruturada } \\
\text { individual }\end{array}$ & $\begin{array}{l}\text { Entrevista semiestruturada com as auxiliares } \\
\text { participantes, em horário pré-estabelecido por } \\
\text { elas, a fim de não comprometer o } \\
\text { desenvolvimento de suas tarefas. Cada entrevista } \\
\text { levou em média } 30 \text { minutos, foram gravada e } \\
\text { posteriormente transcrita. }\end{array}$ \\
\hline $\begin{array}{c}5 \\
\text { O teste } \\
\text { situacional }\end{array}$ & $\begin{array}{l}\text { Teste situacional composto de } 10 \text { situações } \\
\text { problemas com } 3 \text { tipos de respostas que o } \\
\text { profissional de educação poderia vir a ter e para } \\
\text { cada questão } 4 \text { alternativas: concorda muito, } \\
\text { concorda, discorda muito e discorda. }\end{array}$ \\
\hline
\end{tabular}

Fonte: Ribeiro, 2020, p.120

Vale ressaltar que as atividades desenvolvidas nesta etapa desencadearam reflexões e alterações no contexto em pesquisa, fato que integra uma pesquisa-ação. 


\subsection{Análise dos Dados}

Os dados foram analisados através de categorias a priori extraídas da literatura, e em categorias empíricas, geradas pelo próprio estudo. Os dados foram analisados, interpretados e agrupados considerando suas caracteristicas e semelhanças (Bardin, 2009).

\section{Resultados e Discussão}

Os dados coletados na etapa exploratória, aqui apresentada, possibilitaram verificar e examinar relações existentes na prática cotidiana das participantes, bem como planejar as atividades futuras.

A análise da entrevista aberta em grupo focal trouxe a visão do grupo participante quanto a maneira que notavam o seu próprio trabalho. Os termos apresentados pelo grupo foram (Figura 1):

Fig. 1. Visão do auxiliar em relação ao trabalho desenvolvido

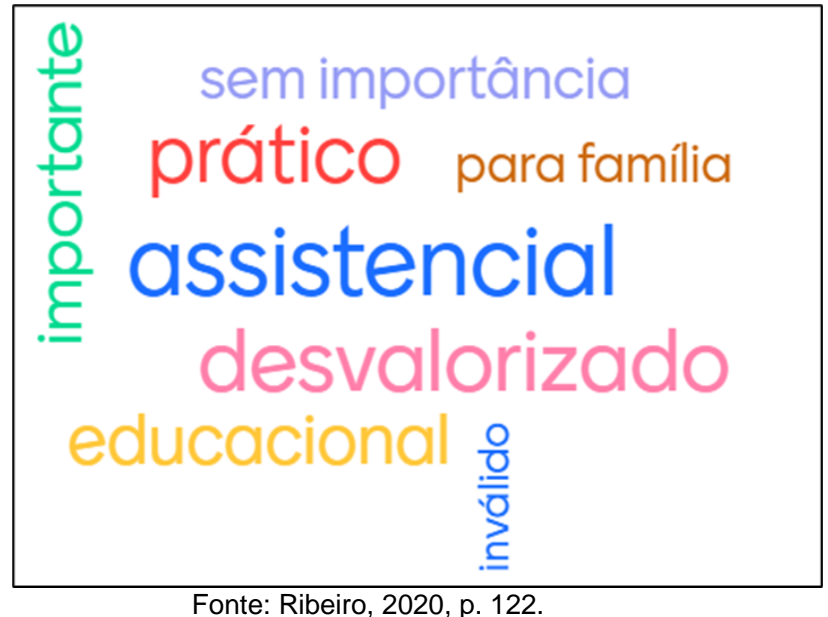

Por meio destas palavras podemos afirmar que embora tenhamos pontos positivos, os maiores índices (Figura 2) referem-se a aspectos considerados pelo grupo como negativos, entre eles, no caso, o assistencial, que para as participantes não remete a uma proposta educacional.

Fig. 2. Índice referente a visão do auxiliar de educação sobre o trabalho desenvolvido

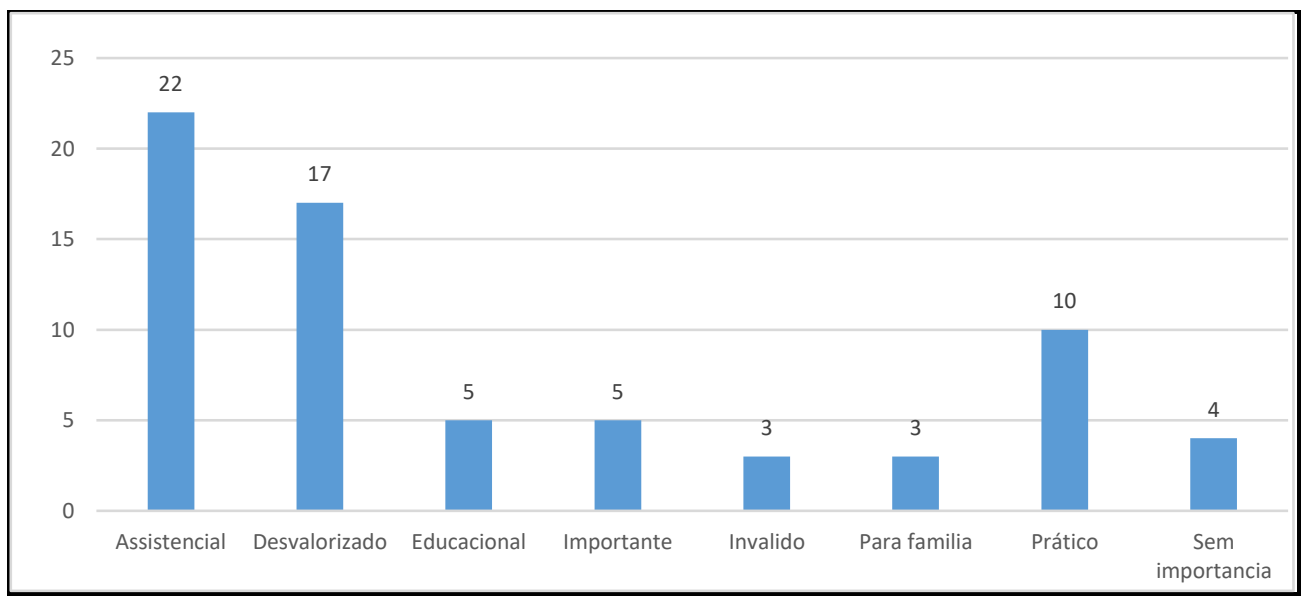

Fonte: Ribeiro. 2020, p. 123 
De acordo com Ribeiro (2020) a partir da década de 90, no Brasil, o cuidar e educar passam a ser objetivos indissociáveis da educação infantil. Porém, a história da educação infantil no Brasil é marcada por ideias que denota uma separação entre os objetivos indicados gerando um grande desafio ao contexto educacional, desconsiderando a relação pertinente entre ambos para garantir o pleno desenvolvimento da criança. Visto o sentimento apresentado pelo grupo, ao adentrar o contexto educacional através da observação participante notou-se a falta de materiais apropriados para a realização do trabalho e, também, o pequeno número de profissionais frente ao número de tarefas.

Considerando os dados obtidos julgou-se necessário a análise do Edital de Concurso Público para o Cargo de Auxiliar de Educação, verificando-se assim as tarefas de responsabilidade do auxiliar e as exigências relativas à formação do mesmo para a execução de seu trabalho. Esta análise propiciou apurar a ligação entre as informações anteriores e o exigido para tal função.

$\mathrm{Na}$ figura 3 verifica-se a categorização das tarefas descritas em assistencial e educacional.

Fig. 3. Categorização de tarefas descritas para o cargo de auxiliar de educação em Edital

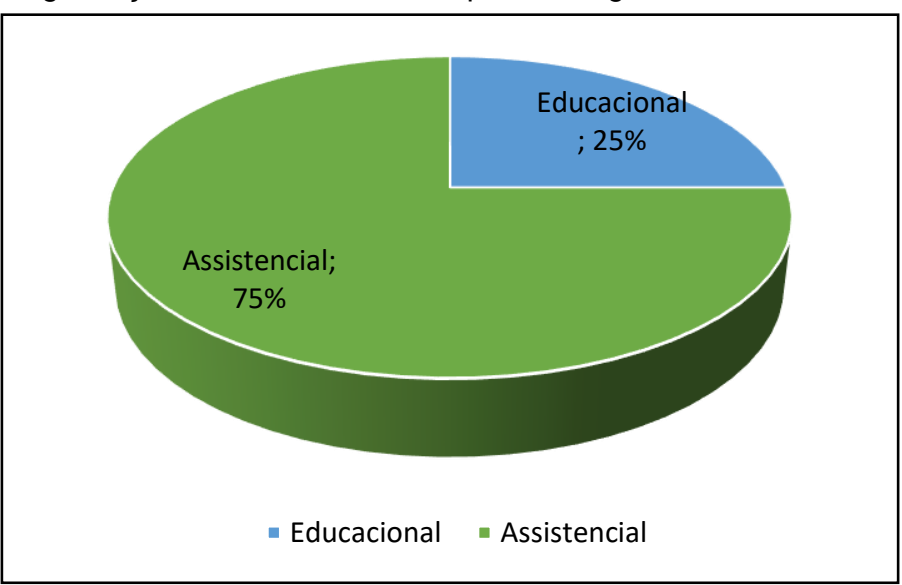

Fonte: Edital de concurso público

Compuseram as categorias indicadas: prestar cuidados de higiene, limpeza da creche, administrar alimentação conforme cardápio padronizado, ministrar medicamentos e, estimular as crianças a serem independentes, incentivar as brincadeiras, entre outras.

Embasados pelos dados coletados, deu-se início as entrevistas semiestruturadas individuais. As respostas obtidas foram transcritas e agrupadas de acordo com a semelhança entre suas características. Com relação as questões destacamos:

Quadro 2. Transcrição de algumas respostas das auxiliares para questão: Desejava trabalhar com crianças de 0 a 2 anos de idade?

1. Não. A gente não sabe o que vai pegar né. Ah, eu teria escolhido maior... teria escolhido.
Eu amo o berçário, mas é uma parte que deixava a gente... eu no começo chorava, falava, o que
eu estou fazendo aqui? Isso porque eu sabia trocar fralda, sabia dar banho, por experiência em
casa. Mas, na hora que você vê aquele monte de criança, assim, você... eu tinha medo da criança
se engasgar, nossa... no dormitório, eu ficava de berço em berço olhando para ver se eles estavam
respirando.
$2 . \quad$ Eu queria trabalhar com criança grande. Mas, daí surgiu a oportunidade e ... eu acho que
tudo é experiência né?... E até hoje estou aqui.
$3 . \quad$ Ah, na realidade quando eu entrei, eu ainda não tinha muita ideia de idade. Hoje, se você
perguntar, a minha vontade era trabalhar com crianças maiores. Apesar de amar essa faixa etária,
eu tenho vontade de trabalhar com crianças maiores, eu tenho.
$4 . \quad$ Ah, eu sempre gostei de criança. Mas, nunca pensei em trabalhar diretamente com elas.
$5 . \quad$ Sim, tinha esse objetivo de trabalhar no berçário mesmo. O que eu sempre quis foi o
berçário.

Fonte: Ribeiro, 2020, p.131 
Neste caso, foi possível notar categorias que indicaram inclusive o desejo ou não em permanecer realizando esta atividade profissional.

Tabela 1. Desejo e permanência no atendimento à criança de 0 a 2 anos de idade

\begin{tabular}{|c|c|c|}
\hline Desejava trabalhar com crianças de 0 a 2 anos de idade? & $\mathbf{f}$ & $\%$ \\
\hline Possuía esse desejo por gostar de crianças & 5 & $13 \%$ \\
\hline Não possuía esse desejo & 14 & $37 \%$ \\
\hline $\begin{array}{l}\text { Deseja continuar atendendo a crianças pequenas ( } 0 \text { a } 2 \\
\text { anos de idades) }\end{array}$ & 11 & $29 \%$ \\
\hline Deseja atender crianças com mais de 4 anos de idade & 4 & $11 \%$ \\
\hline Indiferente & 4 & $11 \%$ \\
\hline Total & 38 & $100 \%$ \\
\hline
\end{tabular}

Fonte: Ribeiro, 2020, p.132

$\mathrm{Na}$ fala das participantes é possível notar no que tange ao desejo inicial de atender a crianças pequenas que $13 \%$ manifestaram como motivo o "gostar de crianças". Explicação que não elucida "a paixão de conhecer" indicada por Freire (2005) necessária ao contexto educacional. Os dados apresentados, permitiram verificar também que a maioria das participantes, ao iniciar seu trabalho, não desejavam atender a crianças pequenas. Porém a partir do momento que tiveram contato com essa experiência, $29 \%$ dos profissionais decidiram por permanecer atendendo essa faixa etária.

Outra questão foi com relação a formação recebida para exercer tal função. A esse respeito:

Quadro 3. Transcrição de algumas respostas das auxiliares para a questão: Qual formação recebeu para realizar suas atividades profissionais com crianças pequenas?

1. Foi meio jogado. Tive ótimas companheiras, tive professoras. Tenho uma amiga que até hoje a gente conversa. Foi minha primeira companheira de classe, ela me ensinou bastante coisa, assim, como lidar com as crianças, conversar, trocar fralda, desfralde, tudo isso.

2. A gente é comunicada que passou no concurso. Eles te chamam: você vai para a escola, só. Não dá um preparo, não dá um respaldo, eu não tive. (Por parte do Departamento)

3. Minha mãe trabalhava na área da educação e quando eu ficava de férias eu ia com minha mãe trabalhar na escola. Então foi uma coisa assim, nata.

4. Sou mãe né! Então a gente já sabe cuidar das crianças.

Fonte: Ribeiro, 2020, p.132

O resultado encontrado mostrou que a formação aconteceu a partir do apoio de outros profissionais com experiência prática no contexto em questão (47\%). Das dezenove entrevistas realizadas, não foi referenciado a formação acadêmica, ou seja, a relação entre a prática e os conteúdos de estudos (teoria). Na tabela 2 é possível verificar a frequência de respostas indicadas pelas participantes.

Tabela 2. Formação recebida para realização de atividades com crianças pequenas

\begin{tabular}{|c|c|c|}
\hline $\begin{array}{l}\text { Qual formação recebeu para realizar suas atividades } \\
\text { profissionais com crianças pequenas? }\end{array}$ & f & $\%$ \\
\hline Orientação de outras auxiliares & 9 & $47 \%$ \\
\hline Observação do contexto educacional & 7 & $37 \%$ \\
\hline Experiência materna & 3 & $16 \%$ \\
\hline Total & 19 & $100 \%$ \\
\hline
\end{tabular}

Fonte: Ribeiro, 2020, p.133 
Por vez, ao se tratar da satisfação ao realizar o trabalho nota-se:

Quadro 4. Transcrição de algumas respostas das auxiliares para a questão: Sente-se satisfeito com o trabalho que realiza?

1. Eu gostaria de ser melhor do que eu sou, entendeu? Eu acho assim, não que a gente não queira fazer, sabe, eu acho que o tempo. É muita criança, você tem que cuidar entendeu? Tem o trabalho de cuidar, mas a gente procura fazer o melhor.

2. Para eles (família) o meu serviço é fazer a parte deles, eles não reconhecem é muito difícil. Não, não somos valorizadas

3. Não. Porque eu queria ser professora. Eu estudei para ser professora.... Eu não consigo ver uma professora no B1.

Fonte: Ribeiro, 2020, p.133

Entre as colocações:

“... eu gosto de estar aqui porque é uma experiência trabalhar com bebês..., mas, eu sou professora, sou formada em pedagogia e eu queria dar aula né. Meu sonho mesmo é dar aula. Aqui estou realizada em partes então, vamos dizer assim." (In. Ribeiro, 2020, p.134).

Resposta que aponta para o distanciamento ainda existente entre a ideia de criança pequena e seu desenvolvimento. Fato que desconsidera, como explica Piaget e Inhelder (1988), a estimulação necessária nesta fase da vida.

A partir dos motivos de insatisfação apresentados, 3 categorias foram elencadas como mostra a tabela 3:

Tabela 3. Motivo da insatisfação no contexto educacional de 0 a 2 anos de idade

\begin{tabular}{lcc}
\hline $\begin{array}{l}\text { Qual o motivo para sentir-se insatisfeito com o } \\
\text { trabalho que realiza? }\end{array}$ & $\mathbf{f}$ & $\%$ \\
\hline Falta de condições para realização do trabalho & 11 & $34 \%$ \\
Idade das crianças & 9 & $28 \%$ \\
Desvalorização da comunidade & 12 & $38 \%$ \\
$\quad$ Total & $\mathbf{3 2}$ & $\mathbf{1 0 0 \%}$ \\
\hline
\end{tabular}

Fonte: Ribeiro, 2020, p.134

Das participantes, $34 \%$ demonstraram insatisfação devido à falta de recursos como: a falta de funcionários e grande número de crianças por auxiliar, remetendo as informações obtidas através da observação participante.

Neste momento, através de um teste situacional, foi possível notar que a maior parte das auxiliares necessitavam de uma formação específica para solucionarem os conflitos de maneira a possibilitar o desenvolvimento da criança e, também, otimizar sua rotina diária. Das participantes apenas uma auxiliar atingiu um percentual maior que $50 \%$, sendo a média geral entre os participantes de $36 \%$ de acertos. Como assegura Rossetti-Ferreira (1998) na relação com a criança estaremos sempre assumindo um papel fundamental com vista a necessidade do sujeito. Em outras palavras, a atuação (a tomada de decisão) do profissional de educação deve atender as necessidades da criança favorecendo seu desenvolvimento.

\section{Conclusões}

Um dos interesses desta etapa da pesquisa foi conhecer a visão do educador da primeira infância frente à importância do seu prórprio trabalho. Através dela pôde ser notado que "a educação que se pratica na atualidade não é simplesmente o resultado das necessidades sociais do presente, mas responde também à história da função educativa" (Delval, 2007, p.21). 
Com base na análise qualitativa concluiu-se também que:

- O cuidar com vista ao atendimento assistencial ainda direciona de forma predominante o funcionamento das unidades escolares participantes deste estudo.

- O não conhecimento do desenvolvimento da criança pequena não propicia práticas favoráveis à construção da inteligência da criança no período sensóriomotor.

- O auxiiar de educação ao sentir-se desvalorizado, não observa a importância de sua atuação para o desenvolvimento da criança pequena.

- A valorização profissional através de um plano de carreira específico, de projetos de formação e condições de trabalho se faz inerente e de direito dessas profissionais. (Ribeiro, 2020, p.135).

Considera-se que este estudo despertou o interesse da comunidade local (equipe escolar e famílias) para a importância do desenvolvimento da criança de 0 a 2 anos de idade, tal como para a relação existente entre a prática educacional e a formação do profissional (Ribeiro, 2020).

A metodologia de pesquisa utilizada possibilitou não apenas conhecer o contexto educacional e a relação entre as auxiliares e o desenvolvimento das crianças de 0 a 2 anos de idade, mas, encontrar a complexidade que norteia este cenário, exaltando através interrogativas que vão além das hipóteses anteriormente estabelecidas, sobrepondo aspectos particulares do contexto em análise. Em outras palavras, a importância de investigar o contexto educacional a partir do olhar de quem o compõe (Ribeiro, 2020).

Finalmente, nota-se também a relevância de ouvir as expectativas e concepções das famílias quanto às necessidades das crianças pequenas, bem como observar como vem acontecendo a construção do conhecimento pela criança em contexto educacional (Ribeiro, 2020). Acredita-se que estes possam ser objetos de pesquisas futuras, ampliando a compreensão de situações vivenciadas através de um novo ciclo de reflexão e ação.

\section{Agradecimentos}

"O presente trabalho foi realizado com apoio da Coordenação de Aperfeiçoamento de Pessoal de Nível Superior - Brasil (CAPES) - Código de Financiamento 001”.

\section{Referências}

Baptista, M.N \& Campos, D.C. (2015). Metodologias de Pesquisa em Ciências: Análises quantitativa e qualitativa. Rio de Janeiro: LTC.

Bardin, L. (2009). Análise de conteúdo. Lisboa: Edições 70.

Bujes, M.I.E. (2001). Escola infantil: Pra que te quero?. In Craidy, C.M \& Kaercher, G.E.P.S (Eds), Educação Infantil: Pra que te quero? (pp. 13-22). Porto Alegre: Artmed.

Coutinho, A.M.S. (2002). Educação Infantil: espaço de educação e cuidado. 25a Reunião Anual da ANPEd. Caxambu. Recuperado em 13 abril, 2020, de 25reunião.anped.org.br

Delval, J. (2002). Introdução à prática do método clínico: descobrindo o pensamento da criança. Porto Alegre: Artmed.

Freire, P. (2005). Professora sim, tia não. Editora: Olho Mágico.

Gil, A.C. (1987). Métodos e técnicas de pesquisa social. São Paulo: Atlas.

Kitzinger, J. (2000). Focus groups with user and providers care. In Pope, C \& Mays, N (Eds), Qualitative research in health care (pp. 20-29). London: BMJ Books.

Kuhlmann Jr, M. (1998). Infância e Educação Infantil. Porto Alegre: Editora Mediação. 
Mantovani de Assis, O.Z \& Mantoan, M.T.E. (2010). Construção das estruturas da inteligência na criança. In Assis, M.C \& Mantovani de Assis, O.Z (Eds), Proepre: Fundamentos teóricos e prática pedagógica para a educação infantil (pp. 23-30). Campinas: Graf FE.

Mantovani de Assis, O.Z \& Assis, M.C. (2003). Proepre: Fundamentos teóricos da educação infantil II. (5 ed.). Campinas: Graf FE.

Piaget, J \& Inhelder, B. (1975). O desenvolvimento das quantidades físicas na criança. Rio de Janeiro: Zahar Editores.

Piaget, J. \& Inhelder, B. (1988). Psicologia da primeira infância: desenvolvimento psíquico desde o nascimento até os 7 anos . In Katz et al (Eds), Psicologia das Idades: do nascimento à morte (pp. 31-64). São Paulo: Editora Manole LTDA.

Ramozzi-Chiarottino, Z. (1988). Psicologia e Epistemologia Genética de Jean Piaget. São Paulo: EPU.

Renner, E. (Diretora). (2016). O começo da vida. [Television programme]. Brasil: Netflix

Ribeiro, C.P. (2020). O contexto educacional e o desenvolvimento da inteligência da criança no período sensório-motor. Dissertação de mestrado, Universidade Estadual de Campinas, Campinas, SP: Brasil.

Rossetti-Ferreira, M.C et al. (1998). Os fazeres na educação infantil. São Paulo: Cortez.

Sadín Esteban , M.P. (2003). Investigación Cualitativa en Educación: Fundamentos y Tradiciones. Madrid: MC Graw and Hill Interamericana de España.

Sampieri, R.H et al. (2013). Metodologia de Pesquisa. Porto Alegre: Penso/Mc Graw Hill.

Stringer, E. (1999). Pesquisa-ação. Thousand Oaks, CA: Sage Publications.

Tripp, D. (2005). Pesquisa-ação: introdução metodológica. Educação e Pesquisa, 31(3), 443-466.

Vianna, H.M. (2003). Pesquisa em Educação: a observação . Brasília: Plano Editora. 